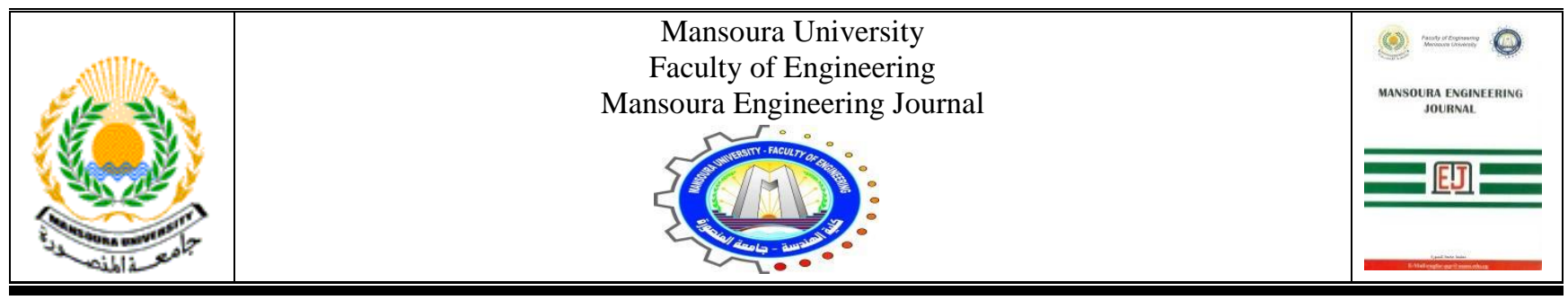

\title{
Performance Evaluation of Stone Matrix Asphalt (SMA) Mixes Using Different Types of Fibers as Additives
}

\begin{tabular}{|lr|}
\hline KEYWORDS: \\
Stone matrix & asphalt, \\
hot mix & asphalt, \\
fiberglass, polypropylene \\
fiber, nominal maximum \\
aggregate r size, \\
Marshall, & Indirect \\
tensile & strength, \\
draindown. & \\
& \\
& \\
& \\
\end{tabular}

\author{
Ahmed Essam*, H. Mahdy and K. Kandil
}

\section{INTRODUCTION}

$\mathrm{N}$ OWADAYS, the field of developing asphalt mixtures has been significantly improved. One of the main concerns is this field is improving

Received: (25 November, 2020) - Revised: (20 December, 2020) Accepted: (31 December, 2020)

*Corresponding Author: Ahmed Essam is a teaching assistant at Department of Public Works, Faculty of Engineering, Ain Shams University, Cairo, Egypt.(email: eng_a.dahab@yahoo.com )

Professor Dr. Hassan Mahdy is a professor of Highways, Transportation, and Traffic at Faculty of Engineering, Ain Shams University, Cairo, Egypt. .(email: drhassanmahdy@gmail.com )

Professor Dr. Khaled Kandil is a professor of Highways, Transportation, and Traffic at Faculty of Engineering, Ain Shams University, Cairo, Egypt. mixture's mechanical properties using additives.

Facing different pavement distresses is one of the main priorities of asphalt mixture's developers all over the world. Rutting is considered as one of the most harmful distressesthat affects pavement.

Rutting by definition is a groove formed into a road or path caused by heavy loaded trucks. Not only ruts affect steering if a vehicle has stuck in the rut, but also it can trap rainwater from moving to sides of the road. Rainwater trapped in ruts is a common contributing factor to hydroplaning crashes (Vargas-nordcbeck, 2016).

Stone matrix asphalt or stone mastic asphalt mixture was first developed and placed in Germany to provide durable surfacing material against permanent deformation distresses like rutting (Holtzheimer \& Mayberg, 2011).

(Ser. No. BFEMU-2011-1077) 
SMA is a gap graded hot mix asphalt. It provides a rut resistant surfacing material depending on stone action between coarse aggregate particles (Irfan, Ali, Ahmed, Iqbal, \&Wang, 2019).

Typical SMA consists of high proportion of both coarse aggregate and fillers coated with high bitumen content.

Due to this high bitumen content, stabilizing additives are needed to prevent binder draindown through transport and placement processes (Putman \& Amirkhanian, 2004).

\section{LITERATURE REVIEW}

Stone matrix asphalt was firstly placed in Kiel, Germany in 1968 as a durable surface hot asphalt mix against rutting, then it spread in many other countries through Europe (Holtzheimer \& Mayberg, 2011).

SMA transferred to USA in a project included using, testing SMA mixes in 20 different states, and comparing the results to conventional aggregate (Waanders \& Els, 1995).

Although SMA mixes proved themselves against rutting, they are not widely used in USA until now because of their high expenses.

As mentioned, due to the high binder content in SMA mixtures, fibers are needed to prevent draindown through transport and placement process.

Different types of fibers have been tested and approved to be effective as additives against draindown especially cellulose fibers and mineral fibers (Irfan, Ali, Ahmed, Iqbal, \&Wang, 2019).

The lack of cellulose and mineral fibers in some countries has open the gates to many studies trying to find an effective local replacement not only to prevent binder draindown, but also to improve SMA characteristics.

\section{A. Different types of fibers tested in SMA mixes}

A study in Brazil used banana fibers as a stabilizing additive in SMA. Four different fiber lengths $5 \mathrm{~mm}, 10 \mathrm{~mm}$, $15 \mathrm{~mm}$, and $20 \mathrm{~mm}$ were tested with fiber content $0.30 \%$. Results showed that samples with fiber lengths 15 and 20 had the best performance in ITS test, flow number, and dynamic modulus (Ferreira Da Costa, Lucena, Lucena, \& Grangeiro De Barros, 2020).

Do Vale, Casagrande, and Soares tested and compared SMA samples with cellulose fibers to samples with coconut fibers at the same fiber content. Although results showed that cellulose fibers had the better influence according to ITS test, moisture susceptibility, and draindown, coconut fibers showed promising results in draindown test which proves its validation to be used (Do Vale, Casagrande, \& Soares, 2014).

A study in Vietnam showed promising results using steel slag as a replacement to conventional aggregate at four different percentages $0.0 \%, 25.0 \%, 50.0 \%$, and $75.0 \%$ (Nguyen \& Le, 2018).

Another study in India tested and compared the results of three different types of fibers coir fibers, sisal fibers, and banana fibers. The main purpose of the study was to determine the optimum fiber content in the mix which was illustrated to be around $0.30 \%$. The mix collapsed and lost its stiffness and strength after increasing fiber content over $0.30 \%$. The conclusion was that coir fiber showed a better value to be used in the mix while sisal and banana fibers were almost the same and had almost the same results at all set tests (Kiran Kumar \& Ravitheja, 2019).

A research in Malaysia tested oil palm fibers to determine optimum oil fiber content to be used by preparing samples with five different fiber contents $0.20 \%, 0.40 \%, 0.60 \%$, $0.80 \%$, and $1.00 \%$ and testing samples through fatigue circle test, stiffness, and ITS test. The results showed that optimum oil palm fiber content for SMA is $0.60 \%$ (Muniandy \& Huat, 2006).

Another researcher tried in his study to know the effect of replacing glass fiber with carbon fiber in SMA and to determine optimum fiber content to be used in the mixture. The conclusion of the study was that optimum fiber content is $0.30 \%$ by total weight of the blend with optimum bitumen content $6.55 \%$. Study declared that stability dropped almost $12.00 \%$ using glass fiber lower than carbon fiber (Karunakar, Sravana, Goud, \& Sowjanya, 2018).

Cloutier and Sobolev tried using coal combustion residuals

like fly ashes to improve mixture's workability and moisture susceptibility. As a result, it was found that using fly ashes in hot asphalt mixes significantly improved mixture's characteristics (Cloutier \& Sobolev, 2016).

Gong et al tested using pre-coated rubber aggregate in SMA mixtures and testing its mechanical properties. The study eventually showed that samples with pre-coated rubber had a better performance in terms of ITS values and strength loss (Gong et al., 2019).

\section{B. Fiberglass applications}

Fiberglass is a material that has been used and tested in various studies.

Depending on the results of a study made in the United States by Graydon, Beatty, Paul, Us, \& Hauck who tried to add fiberglass to the binder to improve some of its chemical properties, the study illustrated that fiberglass tested with a binder with PH less than 3.50 to enhance the binder with catalysts which give a better performance in generating fiberglass products. The conclusion was that using fiberglass binder was found to be useful as it reduces producing difficulties and increases both recovery and rigidity (Graydon, Beatty, Paul, Us, \& Hauck, 2006).

\section{Advantages of SMA Mix}

- Resistance to rutting or permanent deformation. Studies showed that SMA mixes has 30-40\% less permanent deformation than conventional dense mix (Behnood \& Ameri, 2012).

- Good flexibility and resistance to fatigue (Hansen et al., 2000).

- Good durability due to high binder content.

- Good wear resistance (Hainin, Reshi, \& Niroumand, 2012).

- Mechanical properties of SMA mixtures depends on stone on stone contact so it is less sensitive to binder characteristics than conventional dense mix (Brown, et, al, 1997). 
- It can be laid over a rutted or uneven surface because it compresses very little during compaction. This also helps to produce good longitudinal and transverse evenness (Hainin, Reshi, \& Niroumand, 2012), (Nunn, 1994).

- More economical in the long term (Craig Campbell, 1999).

\section{Disadvantages of SMA Mix}

- Increased cost compared to dense mix due to high binder content, high filler content, and fibers cost.

- High filler content can be a reason to reduce productivity.

- Possible delays in opening to traffic as SMA mix should be cooled to $40^{\circ} \mathrm{C}$ to prevent flushing of the binder surface.

- Initial skid resistance may be low (Craig Campbell, 1999).

\section{OBJECTIVES}

The main purposes of this research are to

- Investigate the characteristics of SMA mixtures using fiberglass as a stabilizing additive.

- Compare the performance of SMA mixtures using two different gradations NMAS $12.50 \mathrm{~mm}$ and NMAS $19.00 \mathrm{~mm}$.

- Determine the optimum fiberglass content for each gradation by testing SMA samples at four different fiber contents $0.00 \%, 0.30 \%, 0.50 \%$, and $0.70 \%$.

- Prepare another SMA mix with the best result using polypropylene fiber instead of fiberglass and test it for comparison reasons.

\section{MATERials}

Materials used to prepare SMA mixtures are conventional aggregate, bitumen, and fibers.

\section{A. Conventional aggregate}

Coarse aggregate with two sizes PIN 1 and PIN 2, fine aggregate with both types normal and crushed sand, and fillers were used in this study.

All the conventional aggregate used is dolomitic limestone which was brought by a local contractor from Egypt. Table I shows the results of validation tests of coarse aggregate as well as accepted limitations according to Egyptian Code of Practice (ECP).

TABLE I

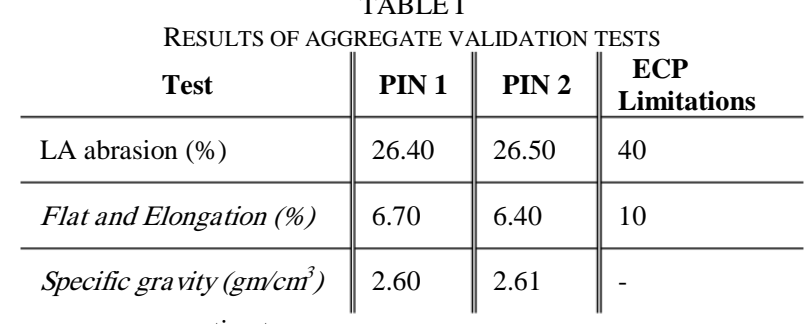

$\mathrm{gm}=$ gram, $\mathrm{cm}=$ centimeter

\section{B. Bitumen}

Bitumen with penetration grade (60/70) was used as it is the common bitumen type in Egypt. It was brought from a refinery located in Suez city, Egypt.

Table II shows the results of validation tests of bitumen as well as accepted limitations according to ECP.

TABLE II

\begin{tabular}{l||l||l}
\multicolumn{1}{c|}{ ReSULTS OF BINDER VALIDATION TESTS } \\
Test & Results & ECP Limitations \\
\hline Penetration (dmm) & 64 & $60-70$ \\
\hline Rotational viscosity & 430 & 320 Minimum \\
\hline Softening point & 49 & $45-55$
\end{tabular}

$\mathrm{dmm}=$ decimillimetre

\section{Fibers}

Both fiberglass and polypropylene fiber were tested with SMA mixes. Both types of fibers are produced by a local company named Chemicals for Modern Building (CMB).

Table III shows polypropylene fibers data sheet according to manufacturing company $\mathrm{CMB}$.

TABLE III

\begin{tabular}{l||l}
\multicolumn{2}{c|}{ POLYPROPYLENE FIBER DATA SHEET } \\
Type & PUre polypropylene \\
\hline Density & $0.91 \mathrm{gm} / \mathrm{cm}^{3}$ \\
\hline \multicolumn{1}{c}{ Color } & White \\
\hline Bundle thickness & $2.00 \mathrm{~mm}$ \\
\hline Cut length & $15.00 \mathrm{~mm}$ \\
\hline Tensile strength & $370 \mathrm{~N} / \mathrm{mm}^{2}$ \\
\hline Modulus of elasticity & $3750 \mathrm{~N} / \mathrm{mm}^{2}$ \\
\hline Elongation at break & $11.00 \%$ \\
\hline Resistance to acids & Very good \\
\hline Resistance to alkalis & Very good \\
\hline Volume resistivity & $>10^{3} \mathrm{ohm}$ \\
\hline Ignition temperature & $>320^{\circ} \mathrm{C}$ \\
\hline
\end{tabular}

\section{TESTING STRATEgY}

To study the behavior of SMA mixtures as a durable surfacing material in Egypt, Two SMA gradations were tested NMAS $12.50 \mathrm{~mm}$ and NMAS $19.00 \mathrm{~mm}$. Both gradations were selected according to AASHTO specifications.

Tables IV and $\mathrm{V}$ show SMA mixtures gradation limits according to AASHTO Designation: M 325-08.

Table VI shows gradations accepted tolerances for extracted SMA samples according to National Cooperative Highway Research Program (NCHRPT) Report 425.

Validation tests were conducted on both aggregate and binder and the results were checked according to ECP. 
All SMA mixtures were designed using Marshall mix design method and compacted using Marshall hammer device.

TABLE IV

BLEND GRADATION FOR SMA WITH NMAS 12.50 MM ACCORDING TO AASHTO LIMITS

\begin{tabular}{l||l||l||l}
\multicolumn{1}{c||}{ Sieve size $(\mathbf{m m})$} & $\begin{array}{l}(\%) \text { Passing } \\
\text { Lower limit }\end{array}$ & $\begin{array}{l}(\%) \text { Passing } \\
\text { Upper limit }\end{array}$ & $\begin{array}{l}(\%) \text { Passing } \\
\text { Blend }\end{array}$ \\
\hline 25.40 & 100.0 & 100.0 & 100.0 \\
\hline 19.00 & 100.0 & 100.0 & 99.6 \\
\hline 12.50 & 90.0 & 100.0 & 92.9 \\
\hline 9.50 & 50.0 & 80.0 & 79.2 \\
\hline 4.75 & 20.0 & 35.0 & 23.0 \\
\hline 2.36 & 16.0 & 24.0 & 19.5 \\
\hline 0.60 & - & - & - \\
\hline 0.30 & - & - & - \\
\hline 0.15 & - & - & - \\
\hline 0.15 & 8.0 & 11.0 & \\
\hline 0.12 & &
\end{tabular}

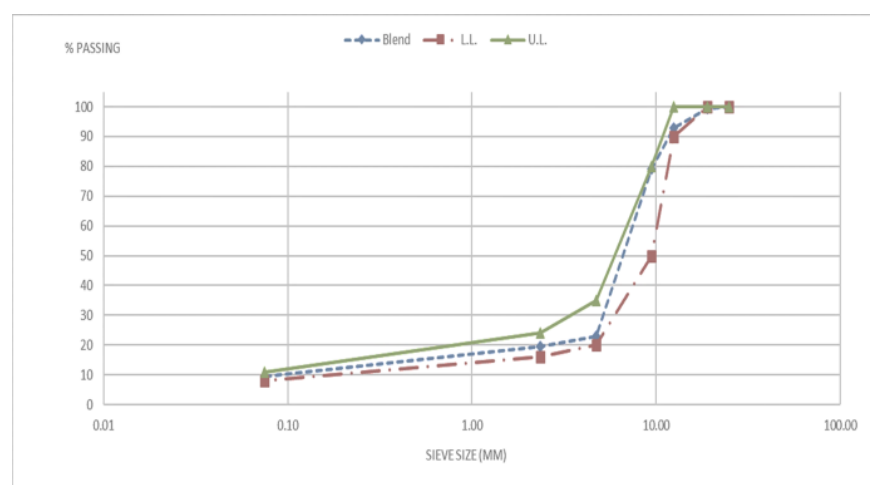

Fig. 1. Gradation of SMA mixtures with NMAS $12.50 \mathrm{~mm}$.

TABLE V

BLEND GRADATION FOR SMA WITH NMAS 19.00 MM ACCORDING TO AASHTO LIMITS

\begin{tabular}{l||l||l||l}
\multicolumn{1}{c||}{ Sieve size $(\mathbf{m m})$} & $\begin{array}{l}(\%) \text { Passing } \\
\text { Lower limit }\end{array}$ & $\begin{array}{l}(\%) \text { Passing } \\
\text { Upper limit }\end{array}$ & $\begin{array}{l}(\%) \text { Passing } \\
\text { Blend }\end{array}$ \\
\hline 25.40 & 100.0 & 100.0 & 100.0 \\
\hline 19.00 & 90.0 & 100.0 & 97.7 \\
\hline 12.50 & 50.0 & 88.0 & 67.5 \\
\hline 9.50 & 25.0 & 60.0 & 52.4 \\
\hline 4.75 & 20.0 & 28.0 & 22.9 \\
\hline 2.36 & 16.0 & 24.0 & 19.5 \\
\hline 0.60 & - & - & - \\
\hline 0.30 & - & - & - \\
\hline 0.15 & - & - & - \\
\hline 0.15 & - & - & - \\
\hline 0.12 & 8.0 & 11.0 & 9.5
\end{tabular}

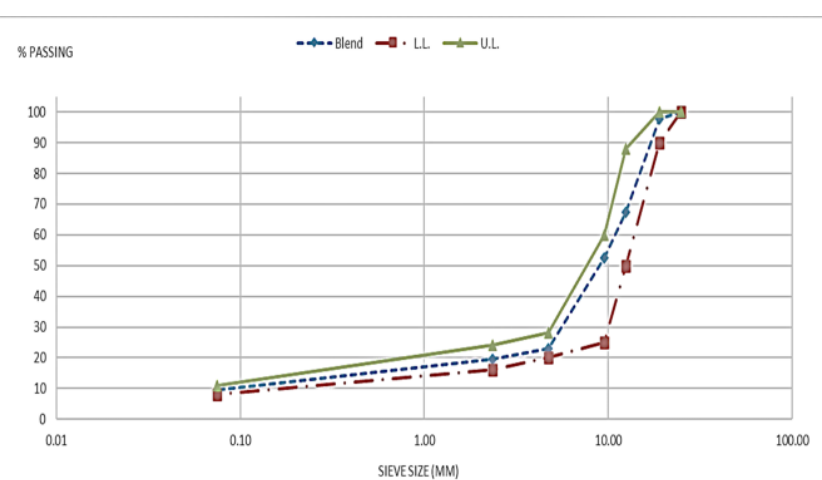

Fig. 2. Gradation of SMA mixtures with NMAS $19.00 \mathrm{~mm}$.

TABLE VI

GRADATION ACCEPTED TOLERANCES FOR SMA SAMPLES

\begin{tabular}{l||l} 
Sieve size $(\mathbf{m m})$ & \multicolumn{1}{c}{$\begin{array}{c}\text { Tolerance for } \\
\text { percent passing } \\
(\boldsymbol{\%})\end{array}$} \\
\hline 25.40 & \pm 4.00 \\
\hline 19.00 & \pm 4.00 \\
\hline 12.50 & \pm 4.00 \\
\hline 9.50 & \pm 4.00 \\
\hline 4.75 & \pm 3.00 \\
\hline 2.36 & \pm 3.00 \\
\hline 0.60 & \pm 3.00 \\
\hline 0.30 & \pm 3.00 \\
\hline 0.15 & \pm 3.00 \\
\hline 0.15 & \pm 3.00 \\
\hline 0.12 & \pm 2.00
\end{tabular}

For each gradation, a control mix with fiberglass content $0.30 \%$ by total weight of the mix used to determine optimum bitumen content as it is the minimum fiber content to be used in SMA mixes according to AASHTO specifications. Table VII shows SMA specifications for Marshall compacted designs according to AASHTO Designation: M 325-08.

TABLE VII

SMA SPECIFICATIONS FOR MARSHALL COMPACTED DESIGNS

\begin{tabular}{l||l}
\multicolumn{1}{c||}{ Property } & \multicolumn{1}{c}{ Requirements } \\
\hline Asphalt content (\%) & 6.0 Minimum \\
\hline Air voids (\%) & 4.0 \\
\hline Voids in Mineral Aggregate (VMA) (\%) & 17.0 Minimum \\
\hline Stability (kg) & 635 Minimum \\
\hline Draindown (\%) & 0.30 Maximum \\
\hline Recommended Marshall hammer blows & 50.0
\end{tabular}

To assemble SMA mixes, virgin aggregate was heated to mixing temperature same as bitumen. Fiberglass was added to 
the heated aggregate and mixed manually until fibers were visually well distributed among aggregate particles then bitumen was added to the mix and rapidly mixed with aggregate and fibers.

Slightly longer mixing times may be added due to the increase surface area added by filler and fiber. Increasing mixing time by 10 secs more than usual mixing time for conventional dense mix visually showed a better confining for aggregate particles and fibers with bitumen.

Best fiber distribution through aggregate particles was noticed when fiber length was $10 \mathrm{~mm}-20 \mathrm{~mm}$ long.

Five different samples with 5 different bitumen contents were prepared to obtain optimum bitumen content. For NMAS $12.50 \mathrm{~mm}, 6.55 \%$ bitumen content was used and $6.25 \%$ for NMAS $19.00 \mathrm{~mm}$. Tables VIII and IX show Marshall mix design results for both gradations NMAS $12.50 \mathrm{~mm}$ and $19.00 \mathrm{~mm}$.

TABLE VIII

MARSHALL MIX DESIGN RESULTS FOR NMAS 12.50 MM

\begin{tabular}{l||l}
\multicolumn{1}{c||}{ Property } & \multicolumn{1}{c}{$\begin{array}{l}\text { Marshall mix } \\
\text { design results }\end{array}$} \\
\hline Optimum bitumen content (\%) & 6.55 \\
\hline Mix specific gravity (gm/ $\left./ \mathrm{cm}^{3}\right)$ & 2.31 \\
\hline Air voids (\%) & 4.00 \\
\hline Voids in Mineral Aggregate (VMA) (\%) & 17.75 \\
\hline Stability $(\mathrm{kg})$ & 1020 \\
\hline Flow (mm) & 2.75
\end{tabular}

TABLE IX

MARSHALL MIX DESIGN RESULTS FOR NMAS 19.00 MM

\begin{tabular}{l||l}
\multicolumn{1}{c||}{ Property } & \multicolumn{1}{|c}{$\begin{array}{l}\text { Marshall mix } \\
\text { design results }\end{array}$} \\
\hline Optimum bitumen content (\%) & 6.25 \\
\hline Mix specific gravity $\left(\mathrm{gm} / \mathrm{cm}^{3}\right)$ & 2.34 \\
\hline Air voids (\%) & 4.30 \\
\hline Voids in Mineral Aggregate (VMA) (\%) & 18.15 \\
\hline Stability (kg) & 1150 \\
\hline Flow (mm) & 3.75
\end{tabular}

Both gradations were tested at 4 different fiberglass contents $0.00 \%, 0.30 \%, 0.50 \%$, and $0.70 \%$ by total weight of the mix.

SMA samples were tested through series of performance tests selected to be Marshall Stability test, loss of stability test, Indirect Tensile Strength (ITS) test, and draindown test.

Three samples for each fiberglass content were prepared for each performance test. For both gradations, a total of 24 samples were tested and the results are listed below.

\section{RESULTS AND DISCUSSION}

Results for both gradations were compared at same fiberglass content.

\section{A. Results analysis}

Figures 3 to 6 shows the results of performance tests for fiberglass samples at each fiber content.

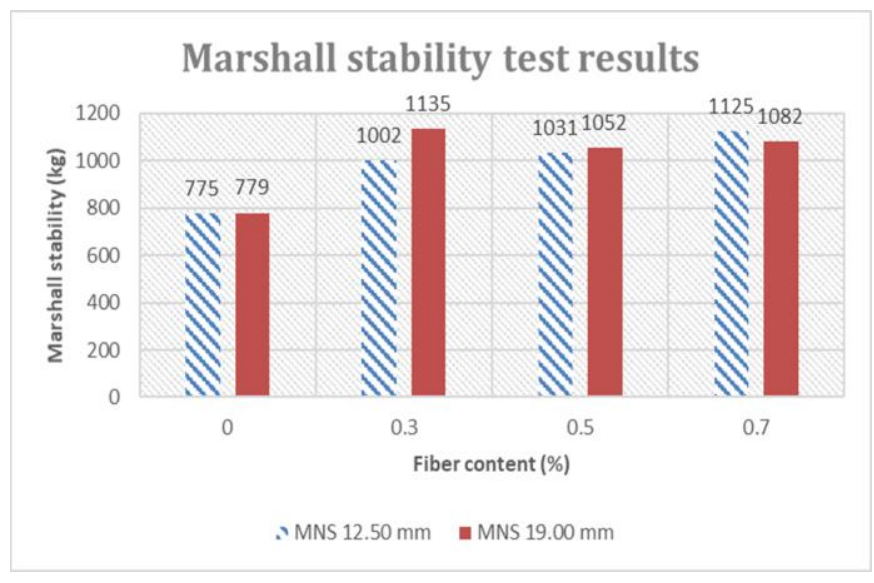

Fig. 3. Stability test results for NMAS $12.50 \mathrm{~mm}$ and $19.00 \mathrm{~mm}$ using fiberglass.

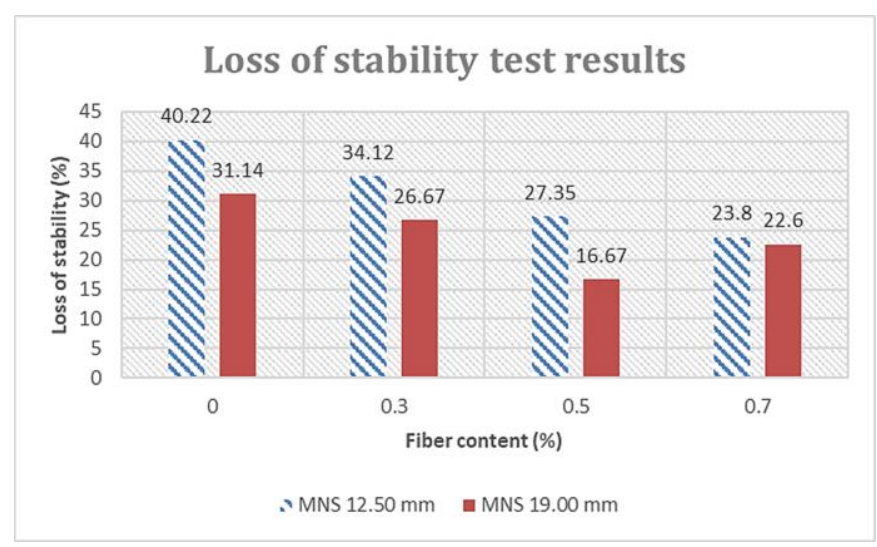

Fig. 4. Loss of stability test results for NMAS $12.50 \mathrm{~mm}$ and $19.00 \mathrm{~mm}$ using fiberglass.

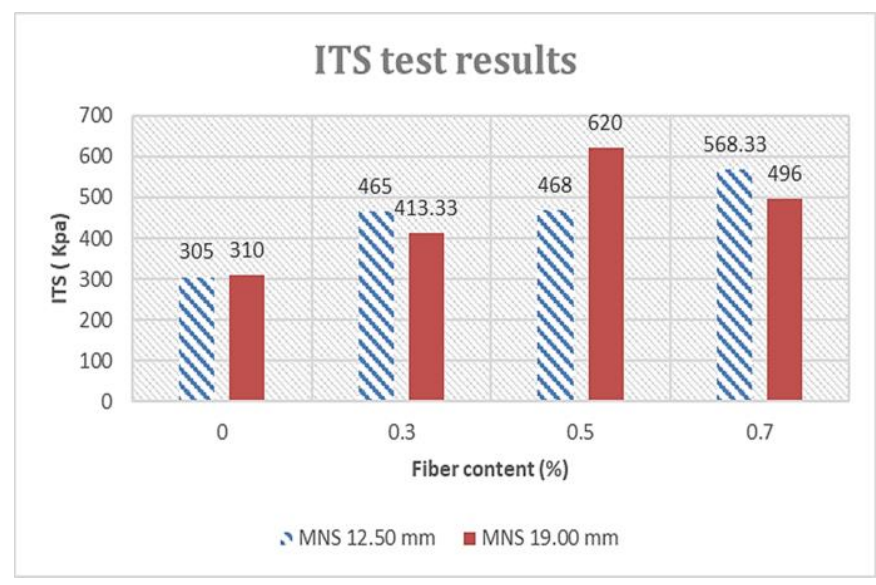

Fig. 5. ITS test results for NMAS $12.50 \mathrm{~mm}$ and $19.00 \mathrm{~mm}$ using fiberglass. 


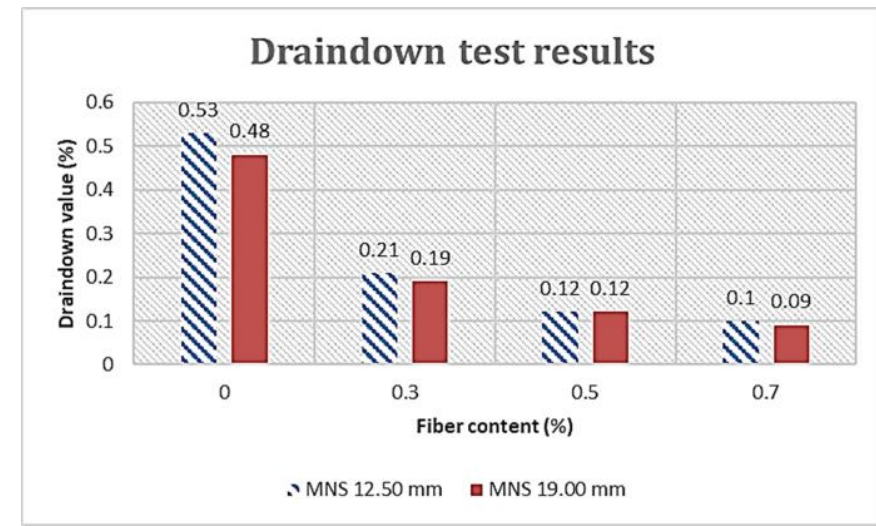

Fig. 6. Draindown test results for NMAS $12.50 \mathrm{~mm}$ and $19.00 \mathrm{~mm}$ using fiberglass.

Figure 3 shows that fibers significantly improved samples stability for both gradations. But for NMAS $12.50 \mathrm{~mm}$, stability increased with the increase of fiber content and the highest stability was for samples with fiber content $0.70 \%$.

On the other hand, for NMAS $19.00 \mathrm{~mm}$, the highest stability was for samples with fiber content $0.30 \%$.

Figure 4 shows that for NMAS $12.50 \mathrm{~mm}$, samples showed same behavior as stability, thus samples with fiber content $0.70 \%$ had the best performance with loss of stability $23.80 \%$.

On the other hand, for NMAS $19.00 \mathrm{~mm}$ samples with fiber content $0.50 \%$ showed the best performance with loss of stability $16.67 \%$.

Figure 5 shows that for ITS test, samples with NMAS $12.50 \mathrm{~mm}$ showed same behavior, thus samples with fiber content $0.70 \%$ had the best performance with $568.33 \mathrm{Kpa}$.

For NMAS $19.00 \mathrm{~mm}$, samples with fiber content $0.50 \%$ once again showed the best performance with $620 \mathrm{Kpa}$.

Figure 6 shows draindown test results and for both gradations, increasing fiber content affected draindown directly as draindown decreases with the increase of fiber content.

Upon analyzing results, it was found that samples with NMAS $19.00 \mathrm{~mm}$ had a better performance than samples with NMAS $12.50 \mathrm{~mm}$.

For NMAS $19.00 \mathrm{~mm}$, SMA mixture with fiber content $0.50 \%$ showed better characteristics than all other mixtures with different fiber contents.

For NMAS $12.50 \mathrm{~mm}$, it was found that mixture characteristics improves with the increase with fiber content, thus a new sample was prepared with fiber content $0.90 \%$ and tested.

Due to the increase of fiber content, it was noticed that air voids ratio has been significantly increased in samples with $0.90 \%$ fibers to reach $6.80 \%$ which is unaccepted for SMA mixture.

The increase of air voids ratio was a result of the unequal fiber distribution through aggregate particles as fibers gathered and coated with bitumen in fat spots through the mix which increased air voids ratio.

Comparing all results, it was noticed that SMA samples for NMAS $19.00 \mathrm{~mm}$ and $0.50 \%$ fiber content had the best characteristics and performance among all tested samples.
Another trial to improve SMA mixture characteristics was done by replacing fiberglass -at the SMA mixture with the best performance- with polypropylene fibers as a stabilizing additive and testing the performance of the new mix and comparing the results to the mix with fiberglass.

Other samples were prepared according to gradation of NMAS $19.00 \mathrm{~mm}$ and with $0.50 \%$ polypropylene fibers and tested through same performance tests. Table $\mathrm{X}$ shows Marshall mix design results for polypropylene samples.

Results showed that mixture characteristics and performance have improved using polypropylene fibers and the results are listed below. Table XI shows the results of performance tested conducted on polypropylene samples.

TABLE X

MARSHALL MIX DESIGN RESULTS FOR NMAS $19.00 \mathrm{MM}$ POLYPROPYLENE FIBER CONTENT $0.50 \%$

\begin{tabular}{l||l}
\multicolumn{1}{c||}{ Property } & \multicolumn{1}{c}{$\begin{array}{l}\text { Marshall mix } \\
\text { design results }\end{array}$} \\
\hline Optimum bitumen content (\%) & 6.25 \\
\hline Mix specific gravity $\left(\mathrm{gm} / \mathrm{cm}^{3}\right)$ & 2.33 \\
\hline Air voids (\%) & 4.16 \\
\hline Voids in Mineral Aggregate (VMA) (\%) & 18.04 \\
\hline Stability (kg) & 1280 \\
\hline Flow (mm) & 3.68
\end{tabular}

To assure the quality of the mixture with polypropylene fibers, more performance tests were conducted on it such as flow number test and wheel track test.

TABLE XI

PERFORMANCE TEST RESULTS FOR SAMPLES WITH NMAS 19.00 MM POLYPROPYLENE FIBER CONTENT $0.50 \%$

\begin{tabular}{l||l}
\multicolumn{1}{c||}{ Property } & \multicolumn{1}{c}{$\begin{array}{c}\text { Marshall mix } \\
\text { design results }\end{array}$} \\
\hline \multicolumn{1}{c||}{ Stability $(\mathrm{kg})$} & 1280 \\
\hline \multicolumn{1}{|l}{ Flow (mm) } & 3.68 \\
\hline Loss of stability (\%) & 9.53 \\
\hline Draindown & $0.10 \%$ \\
\hline Flow number & 135 \\
\hline $\begin{array}{l}\text { Rutting depth } \\
\text { (From wheel track test) }\end{array}$ & $0.88 \mathrm{~mm}$ after \\
\end{tabular}

Results showed that SMA mixture with polypropylene fiber is providing a rut resistant surfacing material according to wheel track test results.

\section{CONClusions}

The main conclusion of this study can be stated in following points 
- SMA samples with NMAS $19.00 \mathrm{~mm}$ showed better performance than samples with NMAS $12.50 \mathrm{~mm}$ in almost all performance tests.

- Changing fiberglass content in the mix can highly affect the performance of the mix as the results showed.

- For NMAS $12.50 \mathrm{~mm}$, it was noticed that SMA samples with fiber content $0.70 \%$ had the best performance.

- Increasing fiber content over $0.70 \%$ leads to increase in air voids ratio due to the unequal fiber distribution in the $\operatorname{mix}$.

- For NMAS $19.00 \mathrm{~mm}$, it was noticed that samples with fiber content $0.50 \%$ had the best performance.

- Comparing all results, it was noticed that SMA samples for NMAS $19.00 \mathrm{~mm}$ and $0.50 \%$ fiber content had the best characteristics and performance among all tested samples.

- Replacing fiberglass with polypropylene fibers significantly improved mixture characteristics.

- After using polypropylene fiber stability reached $1280 \mathrm{~kg}$ comparing to $1052 \mathrm{~kg}$ only with fiberglass.

- Using polypropylene fiber reduced draindown to $0.10 \%$ compared with $0.12 \%$ using fiberglass.

- $\quad$ SMA mixture with polypropylene showed a very good performance at wheel track test -comparing to conventional dense mix- with rutting depth $0.88 \mathrm{~mm}$.

- SMA mixture with NMAS $19.00 \mathrm{~mm}$ and $0.50 \%$ polypropylene fiber content provides a promising durable rut resistant surfacing material.

\section{RECOMMENDATIONS}

- Since it was proved that changing type of fiber used in SMA mixture can affect its performance, thus trying other types of local fibers might be a promising issue to be further tested.

- This study focused on gradations $12.50 \mathrm{~mm}$ and 19.00 $\mathrm{mm}$ thus, it is recommended to compare this study results with NMAS $9.50 \mathrm{~mm}$.

- It is recommended to compact samples using superpave gyratory compactor and compare the results with samples compacted using Marshall hammer.

- Modified binder is highly recommended to be used in SMA mixtures.

\section{AUTHORS CONTRIBUTION}

Ahmed Essam Dahab Abd el Sayed (Teaching assistant at public works department, faculty of engineering, Ain shams university, Cairo, Egypt).

\section{Co-Authors:}

Prof. Dr. Hassan Abd el Zaher Hassan Mahdy (professor of Highways, Transportation, and Traffic at Faculty of Engineering, Ain Shams University, Cairo, Egypt). (Supervision)

Prof. Dr. Khaled Anwar Ahmed Kandil (professor of Highways, Transportation, and Traffic at Faculty of Engineering, Ain Shams University, Cairo, Egypt). (Supervision)

\section{REFERENCES}

[1] AASHTO (2012) A Policy on Geometric Design of Highways and Streets. The American Association of State Highway and Transportation Officials, AASHTO Green Book, Washington DC.

[2] Behnood, A., \& Ameri, M. (2012). Experimental investigation of stone matrix asphalt mixtures containing steel slag. Scientia Iranica, 19(5), 1214-1219. https://doi.org/10.1016/j.scient.2012.07.007

[3] Cloutier, C., \& Sobolev, K. (2016). The effective use of coal combustion products (CCPs) in asphalt pavements. (May).

[4] Do Vale, A. C., Casagrande, M. D. T., \& Soares, J. B. (2014). Behavior of natural fiber in stone matrix asphalt mixtures using two design methods. Journal of Materials in Civil Engineering, 26(3), 457-465. https://doi.org/10.1061/(ASCE)MT.1943-5533.0000815

[5] Fan, T. J. (2010). Rut resistance behavior of pavement structures combined by the different asphalt mixtures. 2010 International Conference on E-Product E-Service and E-Entertainment, ICEEE2010. https://doi.org/10.1109/ICEEE.2010.5660381

[6] Ferreira Da Costa, L., Lucena, L. C. D. F. L., Lucena, A. E. D. F. L., \& Grangeiro De Barros, A. (2020). Use of Banana Fibers in SMA Mixtures. Journal of Materials in Civil Engineering, 32(1). https://doi.org/10.1061/(ASCE)MT.1943-5533.0002994

[7] Gong, F., Guo, S., Chen, S., You, Z., Liu, Y., \& Dai, Q. (2019). Strength and durability of dry-processed stone matrix asphalt containing cement pre-coated scrap tire rubber particles. Construction and Building Materials, 214, 475-483. https://doi.org/10.1016/j.conbuildmat.2019.04.151

[8] Graydon, I., Beatty, E., Paul, S., Us, M. N., \& Hauck, J. A. (2006). ( 12 ) United States Patent. 1(12).

[9] Hainin, R., Reshi, W. F., \& Niroumand, H. (2012). The importance of stone mastic asphalt in construction. Electronic Journal of Geotechnical Engineering, 17 HR, 49-56.

[10] Hansen KR, McGennis RB, Prowell BD, Stonex A. Current and future uses of non-bituminous components of bituminous paving mixtures. Transportation in the New Millennium TRB A2D02, Washington, DC, USA; 2000.

[11] Holtzheimer, P. E., \& Mayberg, H. S. (2011). Stuck in a rut: Rethinking depression and its treatment. Trends in Neurosciences, 34(1), 1-9. https://doi.org/10.1016/j.tins.2010.10.004

[12] Irfan, M., Ali, Y., Ahmed, S., Iqbal, S., \& Wang, H. (2019). Rutting and Fatigue Properties of Cellulose Fiber-Added Stone Mastic Asphalt Concrete Mixtures. Advances in Materials Science and Engineering, 2019. https://doi.org/10.1155/2019/5604197

[13] Karunakar, K., Sravana, P., Goud, K. G., \& Sowjanya, T. (2018) Properties of Stone Matrix Asphalt Using Carbon Fiber and Glass Fiber. International Journal of Engineering Sciences Invention (IJESI), 7(6), $45-52$.

[14] Kiran Kumar, N. L. N., \& Ravitheja, A. (2019). Characteristics of stone matrix asphalt by using natural fibers as additives. Materials Today: Proceedings, 19, 397-402. https://doi.org/10.1016/j.matpr.2019.07.624

[15] Morea, F., Zerbino, R., \& Agnusdei, J. (2013). Improvements on asphalt mixtures rutting performance characterization by the use of low shear viscosity. Materials and Structures/Materiaux et Constructions, 46(1-2), 267-276. https://doi.org/10.1617/s11527-012-9900-8

[16] Muniandy, R., \& Huat, B. B. K. (2006). Laboratory Diameteral Fatigue Performance of Stone Matrix Asphalt with Cellulose Oil Palm Fiber.

[17] Nguyen, M. T., \& Le, A. T. (2018). Performance of Hot Mix Asphalt Concrete When using Electric-Arc Furnace Slag as Natural Coarse Aggregate. Proceedings 2018 4th International Conference on Green Technology and Sustainable Development, GTSD 2018, 831-834. https://doi.org/10.1109/GTSD.2018.8595535

[18] Putman, B. J., \& Amirkhanian, S. N. (2004). Utilization of waste fibers in stone matrix asphalt mixtures. Resources, Conservation and Recycling, 42(3), 265-274. https://doi.org/10.1016/j.resconrec.2004.04.005

[19] Vargas-nordcbeck, A. (2016). The Roles of Accelerated Pavement Testing in Pavement Sustainability. In The Roles of Accelerated Pavement Testing in Pavement Sustainability. https://doi.org/10.1007/978-3-319-42797-3

[20] Waanders, G., \& Els, H. (1995). Splittmastixasphalt und Dränasphalt in den Niederlanden. Erfahrungen und Untersuchungen in der Provinz Overijsel. Asphalt, 95(4), 8-17. 
Title Arabic:

تقييم اداء الخلطات الاسفلتية الحجرية باستخدام انواع مختلفة

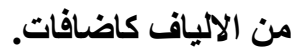

\section{Arabic Abstract:}

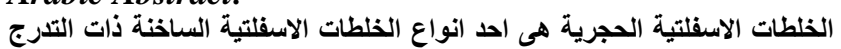

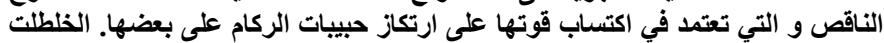

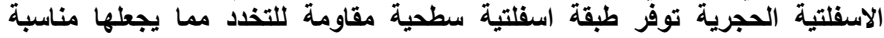
للاستخذام في الطرق ذات الحمولات المرورية العالية.

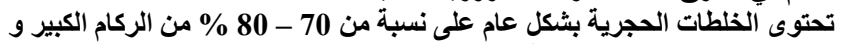

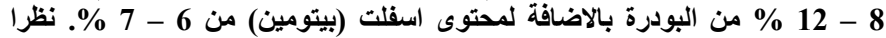

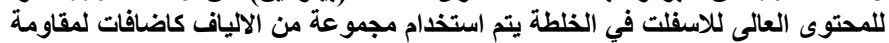
ظاهرة نضوح الاسفلت اثثاء عملية نقل الخلطة و فرشها على الطريق.
طبقا للمواصفات القياسية للخلطات الحجرية فان الالياف السليلوزية او الالياف

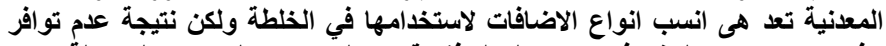

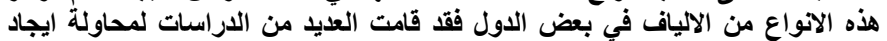
بدائل محليةً صالحة لاستبدالتها في الخلطة.

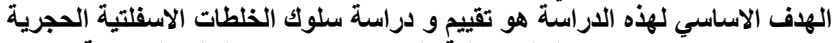

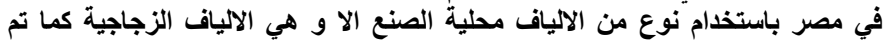
استبدال الالياف الزجاجية بالياف من البولي بروبلين في الخلطة ذات الاداء الافضل

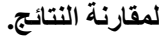
تم اختيار تدرجين من تدرجات الخلطات الحجرية في هذه الاراسة و هم التدرجات

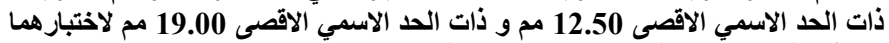

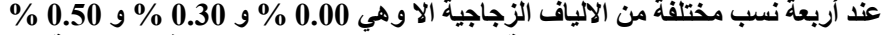

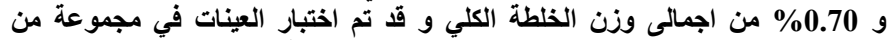

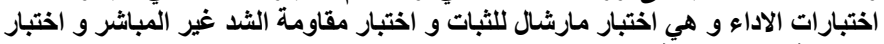
النقص في الثبات و كذنك اختبار نضوح الاسفلت. 